\title{
Identifikasi Tes Kemampuan Verbal Siswa Menurut WISC dengan Tema "Suhu dan kalor dalam Kehidupan" di MTs Plus Az Zahro Cilacap
}

\author{
Siti Fatimah \\ Prodi Pendidikan Fisika Fakulas Sains dan Teknologi UIN Sunan Kalijaga \\ J1. Marsda Adisucipto Yogyakarta \\ Surat-e: stfatimah89@gmail.com
}

\begin{abstract}
Penelitian ini bertujuan untuk menganalisis kemampuan verbal siswa menurut WISC dengan tema "suhu dan kalor dalam kehidupan" berdasarkan standar kurikulum 20I3. Penelitian ini merupakan penelitian deskriptif dengan subjek penelitian siswa kelas VII MTs Plus Az-Zahro Cilacap. Penelitian dirancang dengan memberikan tes kemampuan verbal menurut WISC yang terdiri dari 6 skala verbal yaitu Information (pengetahuan umum), Comprehension (pemahaman), Arithmetic (berhitung), Similarities (kemiripan), Digit span (rentang angka), dan Vocabulary (perbendaharaan kata). Data hasil pemberian tes menunjukkan bahwa $63,40 \%$ peserta didik mampu menyelesaikan soal tes kemampuan verbal di skala pengetahuan umum; 58,29\% peserta didik mampu menyelesaikan soal tes kemampuan verbal di skala pemahaman; 38,72\% peserta didik mampu menyelesaikan soal tes kemampuan verbal di skala berhitung; 40,43\% peserta didik mampu menyelesaikan soal tes kemampuan verbal di skala kemiripan; $28,08 \%$ peserta didik mampu menyelesaikan soal tes kemampuan verbal di skala rentang angka; dan 53,19\% peserta didik mampu menyelesaikan soal tes kemampuan verbal di skala perbendaharaan kata.
\end{abstract}

Kata kunci: maksimal lima kata kunci, pisahkan dengan tanda koma

\section{Pendahuluan}

Intelegensi sangat penting dalam hidup manusia. Intelegensi diartikan sebagai kemampuan dalam menyesuaikan diri dengan lingkungan. Oleh karena itu diperlukan proses belajar dari pengalaman sehingga mampu menyelesaikan masalah dalam berbagai hal. Dalam hidup manusia memiliki banyak intelegensi, salah satunya yaitu kemampuan verbal. Kemampuan verbal merupakan salah satu jenis teori intelegensi yang dikemukakan oleh L.L. Thurstone yang membagi intelegensi menjadi tujuh kemampuan primer. Gagne dalam Winkel[I] membagi peranan dan wujud dari beberapa fase dalam membentuk jalur belajar informasi verbal, yaitu: (I) fase motivasi, cukup berperan bila peserta didik harus mempelajari banyak padanan kata-kata atau banyak fakta; (2) fase mengolah, perlu mendapat tekanan dalam belajar fakta karena fase ini peserta didik mengadakan organisasi yang pada dasarnya berwujud mencari makna yang kemudian dituangkan dalam suatu perumusan verbal; (3) fase menggali, berperan sekali bila fakta yang telah dihafal dimasukkan ke dalam memori untuk dipelajari kembali atau dihubungkan dengan fakta baru; (4) fase prestasi, mengambil wujud menuangkan informasi yang dimiliki dalam perumusan verbal yang tepat. Kondisi-kondisi peserta didik yang belajar informasi verbal, peserta didik harus memiliki motivasi yang tinggi, mampu menggunakan bentuk organisasi yang baik sehingga dapat menguasai teknik-teknik yang sesuai, memiliki ketajaman berpikir dalam menemukan konsep-konsep, memiliki kemampuan untuk membahasakan makna yang ada di dalam konsep agar dapat disimpan dalam memori dalam bentuk yang bermakna [I]. Menurut Jane kemampuan verbal yang terdiri dari bahasa/kata-kata dan rentang angka dipengaruhi oleh kemampuan membaca dan kemampuan memahami kata-kata [2]. Menurut Siti Fatimah terdapat interaksi antara kemampuan verbal dengan prestasi belajar kognitif produk, dan tidak ada interaksi antara kemampuan verbal dengan prestasi belajar proses dan afektif peserta didik. Hal ini menunjukkan bahwa peserta didik yang memiliki kemampuan verbal dengan baik memiliki pengaruh positif terhadap prestasi belajar kognitif produk [3]. Adegbile dan Alabi menyatakan bahwa kemampuan verbal memberikan pengaruh pada prestasi belajar khususnya dalam penulisan essay [4]. Kemampuan verbal dapat diukur dengan beberapa tes intelegensi, salah satunya yaitu dengan menggunakan tes Wechsler. Tes Wechsler 
adalah salah satu tes yang paling terkenal dan memenuhi persayaratan tes yang baik, yaitu memiliki koefisien keterandalan 0,9I. Tes Wechsler untuk usia anak-anak dikenal dengan nama Wechsler Intelligence Scale for Children (WISC).

IPA (Ilmu Pengetahuan Alam) hakikatnya dibangun atas dasar produk ilmiah, proses ilmiah, sikap ilmiah, dan aplikasi. Oleh karena itu, berdasarkan standar kurikulum 2013 proses belajar mengajar khususnya IPA menggunakan pendekatan saintifik dan tematik. Selain proses pembalajaran, dalam pelaksanaan penilaian dilakukan juga secara tematik.

Berdasarkan hasil observasi di MTs Plus Az-Zahro terdapat $80 \%$ peserta didik tidak tuntas KKM (Kriteria Ketuntasan Minimal) pada materi suhu dan kalor. Hasil wawancara dikatakan bahwa peserta didik memiliki kelemahan dalam memahami suhu dan kalor.

\section{Kajian Pustaka}

Menurut Super dan Cites dalam Wasty Soemanto intelegensi adalah kemampuan menyesuaikan diri dengan lingkungan atau belajar dari pengalaman. Garrett menyatakan bahwa intelegensi setidaknya mencakup kemampuan-kemampuan yang diperlukan untuk pemecahan masalah-masalah yang memerlukan pengertian serta menggunakan simbol-simbol [5].

Bischoft dalam Wasty Soemanto menyatakan bahwa intelegensi adalah kemampuan untuk memecahkan segala jenis masalah. Sedangkan Heidenrich menjelaskan bahwa intelegensi menyangkut kemampuan untuk belajar dan menggunakan sesuatu yang telah dipelajari dalam usaha penyesuaian terhadap situasi-situasi yang kurang dikenal [5].

Kemampuan verbal merupakan salah satu jenis teori intelegensi yang dikemukakan oleh L.L. Thurstone yang membagi intelegensi menjadi tujuh kemampuan primer. Kemampuan verbal atau berbahasa adalah kemampuan menangkap ide yang dinyatakan lewat bahasa, kecakapan untuk menggunakan bahasa, verbal factor, dan dilambangkan dengan huruf $\mathrm{V}$.

Menurut Robert M. Gagne dalam Winkel informasi verbal adalah pengetahuan yang dimiliki seseorang dan dapat diungkapkan dalam bentuk bahasa lisan dan bahasa tertulis. Informasi verbal meliputi kata yang dimiliki seseorang untuk menunjuk pada objek-objek yang dihadapi, serta data dan fakta yaitu kenyataan yang diketahui. Tingkat taraf intelegensi seseorang dapat diukur dengan menggunakan tes intelegensi. Salah satu tes untuk mengukur intelegensi dikembangkan oleh David Wechsler [I].
David Wechsler dalam R. L. Atkinson mengembangkan tes dengan nama Wechsler Bellevue Intelligence Scale (WB) dan direvisi pada tahun 1955 dengan nama Wechsler Adult Intelligence Scale (WAIS). Tes yang dikembangkan untuk anak-anak dikenal dengan nama Wechsler Intelligence Scale for Children (WISC). Tes intelegensi ini merupakan salah satu tes yang paling terkenal dan memenuhi persayaratan tes yang baik, yaitu memiliki koefisien keterandalan 0,9I [7].

Skala Wechsler memberikan nilai untuk tiap subtes, sehingga penguji memiliki gambaran yang lebih jelas tentang kekuatan dan kelemahan intelektual seseorang. Tes ini mencakup dua skala yaitu, skala verbal dan skala performance.

Tabel I. Kategori Pengukuran Kecerdasan Wechsler

\begin{tabular}{|c|c|}
\hline Skala Verbal & Skala Performance \\
\hline Information (Pengetahuan Umum) & $\begin{array}{l}\text { Digit Symbol (Simbol } \\
\text { Angka) }\end{array}$ \\
\hline Comprehension (Pemahaman) & $\begin{array}{l}\text { Picture Completion } \\
\text { (Melengkapi Gambar) }\end{array}$ \\
\hline Arithmetic (Berhitung) & $\begin{array}{l}\text { Block Design } \\
\text { (Menyusun Balok) }\end{array}$ \\
\hline Similarities (Kemiripan) & $\begin{array}{l}\text { Picture Arrangement } \\
\text { (Menyusun Gambar) }\end{array}$ \\
\hline Digit Span (Rentang Angka) & $\begin{array}{l}\text { Object Assembly } \\
\text { (Menyusun Benda) }\end{array}$ \\
\hline Vocabulary (Perbendaharaan Kata) & \\
\hline
\end{tabular}

Suhu dan Kalor dalam Kehidupan adalah tema yang ditentukan berdasarkan analisis model-model keterpaduan yaitu menggunakan model keterpaduan tipe Webbed.

\section{Metode Penelitian/Eksperimen}

Penelitian ini merupakan penelitian deskriptif yang menggunakan pendekatan kualitatif. Penelitian ini dilakukan pada peserta didik kelas VII di MTs Plus Az Zahro Cilacap dengan jumlah 47 peserta didik. Instrumen pengambilan data dengan menggunakan lembar tes kemampuan verbal bentuk pilihan ganda dengan jumlah 30 butir soal. Teknik analisis data menggunakan persamaan

$$
K V=\frac{f}{n} \times 100 \%
$$




\section{Hasil Penelitian dan Pembahasan}

a. Hasil tes kemampuan verbal skala information (pengetahuan umum)

Tes kemampuan verbal skala pengetahuan umum dibuat dengan memberikan pertanyaan mengenai pengetahuan umum. Tes bentuk skala pengetahuan umum dalam penelitian ini berjumlah 5 butir soal. Gambar I adalah salah satu contoh bentuk tes kemampuan verbal skala pengetahuan umum. Hasil keseluruhan tes menjukkan bahwa peserta didik mampu menjawab dengan tepat pertanyaan di skala pengetahuan umum yaitu sebesar $63,4 \%$. Hasil tes pada skala ini menunjukkan persentase yang paling tinggi. Peserta didik dapat menjawab dengan tepat. Berdasarkan hasil wawancara menunjukkan bahwa peserta didik tidak mengalami kesulitan dalam menjawab pertanyaan yang bersifat pengetahuan umum. Hal ini dikarenakan peserta didik mampu mengingat informasi-informasi yang sifatnya hafalan.

Satuan suhu menurut standar internasional (SI) adalah ...
a. Celcius
b. Fahrenheit
c. Reamur
d. Kelvin

Gambar I. Tes kemampuan verbal skala information

b. Hasil tes kemampuan verbal skala Comprehension (Pemahaman)

Tes kemampuan verbal skala pemahaman dibuat untuk menguji informasi atau konsep-konsep yang dimiliki peserta didik. Tes bentuk skala pemahaman dalam penelitian ini berjumlah 8 butir soal. Gambar II adalah salah satu contoh bentuk tes kemampuan verbal skala pemahaman. Hasil keseluruhan tes menjukkan bahwa peserta didik mampu menjawab dengan tepat pertanyaan di skala pemahaman yaitu sebesar 58,29\%.

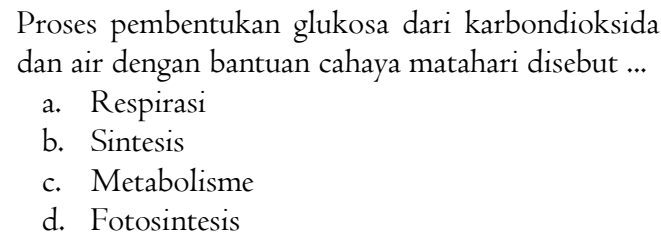

Gambar 2. Tes kemampuan verbal skala comprehension c. Analisis hasil tes kemampuan verbal skala Arithmetic (Berhitung)

Tes kemampuan verbal skala berhitung dibuat untuk menilai penalaran berhitung. Tes bentuk skala berhitung dalam penelitian ini berjumlah 3 butir soal. Gambar 3 adalah salah satu contoh bentuk tes kemampuan verbal skala berhitung. Hasil keseluruhan tes menjukkan bahwa peserta didik mampu menjawab dengan tepat pertanyaan di skala berhitung yaitu sebesar $38,72 \%$.

Neni memanaskan minyak tanah bermassa 200 gram
sehingga suhunya naik menjadi $20^{\circ} \mathrm{C}$. Jika kalor jenis
minyak tanah adalah $2,2 \times 10^{3} \mathrm{~J} / \mathrm{kg}^{\circ} \mathrm{C}$, maka kalor
yang diperlukan untuk memanaskan minyak tanah
tersebut adalah ...
a. $8,8 \times 10^{3} \mathrm{~J}$
b. $8 \times 10^{3} \mathrm{~J}$
c. $0,8 \times 10^{3} \mathrm{~J}$
d. $0,08 \times 10^{3} \mathrm{~J}$

Gambar 3. Tes kemampuan verbal skala arithmetic

d. Analisis hasil tes kemampuan verbal skala Similarities (Kemiripan)

Tes kemampuan verbal skala kemiripan dibuat untuk menanyakan persamaan/kemiripan kata dari suatu objek tertentu. Tes bentuk skala kemiripan dalam penelitian ini berjumlah 2 butir soal. Gambar 4 adalah salah satu contoh bentuk tes kemampuan verbal skala kemiripan. Hasil keseluruhan tes menjukkan bahwa peserta didik mampu menjawab dengan tepat pertanyaan di skala kemiripan yaitu sebesar 40,43\%.

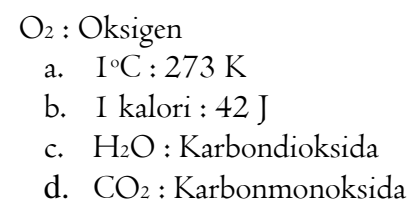

Gambar 4. Tes kemampuan verbal skala similarities

e. Analisis hasil tes kemampuan verbal skala Digit Span (Rentang Angka)

Tes kemampuan verbal skala rentang angka dibuat untuk menanyakan serangkaian angka. Tes bentuk skala rentang angka dalam penelitian ini berjumlah 2 butir soal. Gambar 5 adalah salah satu contoh bentuk tes kemampuan verbal skala rentang angka. Hasil keseluruhan tes menjukkan bahwa peserta didik mampu menjawab dengan tepat pertanyaan di skala rentang angka yaitu sebesar $28,08 \%$. Hasil tes pada skala ini menunjukkan persentase yang paling rendah 
peserta didik dapat menjawab dengan tepat. Berdasarkan hasil wawancara menunjukkan bahwa peserta didik sebenarnya mampu menghitung dengan pertanyaan yang diberikan, namun karena kurang teliti dalam memberikan jawaban dan bingung dengan adanya rentetan angka yang hampir sama/jawaban pengecoh maka banyak peserta didik yang menjawab dengan tidak tepat.

Mufti mengukur suhu air dengan termometer
skala fahrenheit dan menunjukkan angka $23^{\circ} \mathrm{F}$.
Berapakah suhu air tersebut jika dinyatakan
dalam skala reamur, celcius, dan fahrenheit
secara berurutan?
a. $-4^{\circ} \mathrm{R} ;-5^{\circ} \mathrm{C} ; 268 \mathrm{~K}$
b. $4^{\circ} \mathrm{R} ; 5^{\circ} \mathrm{C} ; 268 \mathrm{~K}$
c. $-4^{\circ} \mathrm{R} ; 5^{\circ} \mathrm{C} ; 268 \mathrm{~K}$
d. $-5^{\circ} \mathrm{R} ;-4^{\circ} \mathrm{C} ; 268 \mathrm{~K}$

Gambar 5. Tes kemampuan verbal skala digit span f. Analisis hasil tes kemampuan verbal skala Vocabulary (Perbendaharaan Kata)

Tes kemampuan verbal skala perbendaharaan kata dibuat untuk menguji pengetahuan kata. Tes bentuk skala perbendaharaan kata dalam penelitian ini berjumlah IO butir soal. Gambar VI adalah salah satu contoh bentuk tes kemampuan verbal skala perbendaharaan kata. Hasil keseluruhan tes menjukkan bahwa peserta didik mampu menjawab dengan tepat pertanyaan di skala perbendaharaan kata yaitu sebesar 53,19\%. Berdasarkan hasil wawancara, awalnya peserta didik merasa bingung dengan pertanyaan model seperti ini. Namun dengan dibantu peneliti maka peserta didik mampu menjawab dengan baik pertanyaan tersebut.

\begin{tabular}{|c|c|}
\hline $\begin{array}{l}\text { I. a. Celcuis } \\
\text { c. Fahrenheit }\end{array}$ & $\begin{array}{l}\text { b. Kelvin } \\
\text { d. Termometer }\end{array}$ \\
\hline $\begin{array}{l}\text { 2. a. } \mathrm{H}_{2} \mathrm{O} \\
\text { c. } \mathrm{O}_{2}\end{array}$ & $\begin{array}{l}\text { b. } \mathrm{CO}_{2} \\
\text { d. Cahaya matahari }\end{array}$ \\
\hline
\end{tabular}

Gambar 6. Tes kemampuan verbal skala vocabulary

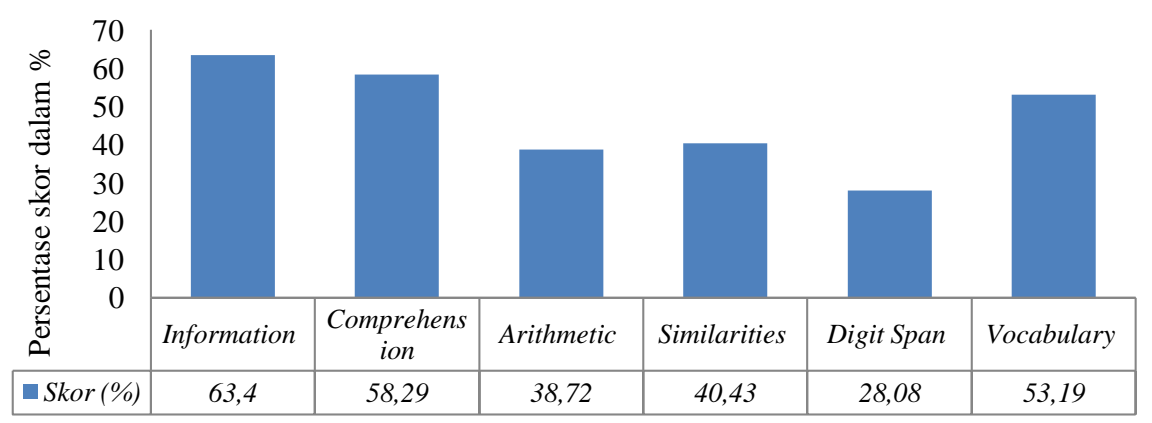

Gambar 7. Perbandingan hasil tes kemampuan verbal menurut Wechsler

\section{Kesimpulan}

Data hasil pemberian tes menunjukkan bahwa 63,40\% peserta didik mampu menyelesaikan soal tes kemampuan verbal di skala pengetahuan umum; 58,29\% peserta didik mampu menyelesaikan soal tes kemampuan verbal di skala pemahaman; $38,72 \%$ peserta didik mampu menyelesaikan soal tes kemampuan verbal di skala berhitung; 40,43\% peserta didik mampu menyelesaikan soal tes kemampuan verbal di skala kemiripan; 28,08\% peserta didik mampu menyelesaikan soal tes kemampuan verbal di skala rentang angka; dan 53,19\% peserta didik mampu menyelesaikan soal tes kemampuan verbal di skala perbendaharaan kata.

\section{Kepustakaan}

[I] Adegbile dan Alabi, Effects Of Verbal Ability On Second Language Writers Achievement In Essay Writing In English Language, Interational Journal of African anf African America Studies. Vol. I No.I., 2007, Hal. 62-67.

[2] Jane Oakhill, dkk.. The Differential Relations Between Verbal, Numerical and Spatial Working Memory Abilities and Children's Reading Comprehension, International Electronic Journal of Elementary Education. Vol. 4 No. I, 20II, Hal. 83-I06.

[3] R. L. Atkinson, R. C. Atkinson, E.E. Smith, dan D. J. Bem, Pengantar Psikologi, Interaksara, 1987.

[4] Siti Fatimah, Pembelajaran Fisika dengan Pendekatan Problem Based Learning (PBL) Menggunakan Modul dan Buletin Ditinjau dari Kemampuan Verbal dan Motivasi Berprestasi Siswa, Magister, Tesis, 2013.

[5] Winkel, Psikologi Pengajaran, Gramedia Widiasarana Indonesia, 1996.

[6] Wasty Soemanto, Psikologi Pendidikan, Rineka Cipta, 2003. 